\title{
Una visión del cuerpo femenino y de la enfermedad a partir de dos diagnósticos médicos, Lima $1803^{1}$
}

\author{
Jesús A. Cosamalón Aguilar \\ El Colegio de México A.C.
}

Este trabajo analiza dos informes médicos emitidos en el contexto de un juicio de divorcio llevado a cabo en Lima, en 1803. María Cabrera solicita y exhibe, como prueba para el litigio, dos diagnósticos acerca de su dolencia de carácter venéreo. A partir de estos documentos se hace posible reconstruir la imagen que la ciencia comienza a generar de la mujer, fundamentada en el nuevo conocimiento de la época. La melancolía, el carácter inestable y débil de la mujer se explican, desde esta perspectiva, por su constitución fisiológica, que hace de ella un ser destinado a la exclusión del espacio público. Por otro lado, la nueva concepción mecanicista del cuerpo se evidencia por medio de los tratamientos médicos, que lo conciben como una máquina susceptible de ser tratada por medio de leyes físicas y químicas.

Palabras Clave: Historia de la vida privada, Historia de la medicina, Divorcio, Historia de la mujer.

This work analyzes two medical reports emitted in the context of a judgement of divorce carried out in the city of Lima in 1803. María Cabrera requests and exhibits, as test for the lawsuit, two diagnoses about her venereal disease. These documents makes possible the reconstruction of the image that science generated about women, based in the new knowledge of the epoch. The melancholy, weak and unstable character of this woman are explained by her physiological constitution that justifies her exclusion of the public space. However, the new mechanistic conception of the body becomes evident in medical treatment, based in the application of chemical and physical laws.

KEYwoRDs: History of Private life, History of medicine, Divorce, Women History.

\section{Un caso excepcional}

En 1803 el capitán de milicias José Rodríguez, vecino y residente de la villa de Santa, al norte de la capital virreinal, solicitó ante el tribunal arzobispal el divorcio de su esposa María Cabrera bajo el argumento de

1 Este trabajo fue realizado como parte del seminario que Pilar Gonzalbo imparte en El Colegio de México A. C.; además, Juan Carlos Estensoro también contribuyó con valiosos comentarios. Laura Gutiérrez, directora del Archivo Arzobispal, me proporcionó información indispensable para llevarlo a cabo. A ellos nuestro agradecimiento por las críticas y sugerencias; naturalmente sólo el autor es responsable por el contenido. 
que ella cometía adulterio con José Coquett, hacendado de la misma villa. Una vez expuesta la denuncia, la mujer fue depositada en el beaterio de las Camilas, mientras que su defensa aducía el padecimiento de una sífilis trasmitida por su marido, enfermedad que él adquirió — según los abogados - antes de casarse y, por tanto, sería José Rodríguez el causante de los males en el matrimonio. Para sustentar su punto de vista, la defensa de María Cabrera recurrió a la opinión autorizada de dos médicos que se encargaron de emitir sus diagnósticos acerca de la enferma. Por otro lado, situación bastante común, se acusa a Rodríguez de tener una criada como amante, llegando incluso a procrear hijos con ella.

Este tipo de documentos han sido analizados en los últimos años desde diversas ópticas. Dado el caudal de información que proporcionan, es posible mediante un estudio sistemático lograr una imagen - aunque sea parcial - de la familia, la sociedad, etc. De hecho, los trabajos que utilizan este tipo de documentación usualmente abordan estos temas, ${ }^{2}$ aunque también se nota un interés en el discurso acerca del género y de las estrategias que se esgrimen ante los tribunales. Menos frecuente es encontrar un análisis acerca de la imagen del cuerpo que se encuentra detrás de estos debates legales. Evidentemente, a veces, la documentación permite un acercamiento a esta temática, dado que no siempre hay la oportunidad de encontrar explícitamente discursos médicos en los juicios.

En el caso que mencionamos la defensa de María Cabrera recurrió al diagnóstico médico como una manera de sustentar su posición ante los tribunales, lo que nos permite conocer el punto de vista de dos médicos acerca del cuerpo de la mujer. "El sexo femenino, digo el bello sexo, es mucho más susceptible de estos padecimientos, pues las más pequeñas dolencias las preocupan y las hacen caer en un entusiasmo". Así inicia su diagnóstico el médico José Figueroa sobre doña María Cabrera. Un año antes que él, Mr. Bonpland, médico de Alexander von

2 Los estudios más interesantes, desde nuestro punto de vista, acerca del tema son: Bustamante Otero, Luis: "El pesado yugo del santo matrimonio: divorcio y violencia conyugal en el arzobispado de Lima (1800-1805)", Histórica, XXV, 1, Lima, 2001, págs. 109-160. Lavallé, Bernard: Amor y opresión en los andes coloniales, Lima, Instituto de Estudios Peruanos, Instituto Francés de Estudios Andinos y Universidad Ricardo Palma, 1999. Flores Galindo, Alberto y Magdalena Chocano: "Las cargas del sacramento", Revista Andina, II, 2, Cusco, págs. 403-423; Lavallé, Bernard: "Divorcio y nulidad de matrimonio en Lima", Revista Andina, IV, 2, págs. 427-464, y Macera, Pablo: Trabajos de Historia, 4 Ts., Lima, Instituto Nacional de Cultura, 1977. ("Sexo y coloniaje", T. III, págs. 297-352). 
Humboldt, ${ }^{3}$ había hecho el mismo diagnóstico, recomendando una serie de medidas para restablecer la salud de doña María. El objeto de ambos diagnósticos es el mismo y varias de la terapias propuestas coinciden. Un médico extranjero y uno local tratan el mismo caso, ambos están comprometidos a expresar los argumentos que sustentan sus recomendaciones y, por tanto, nos permiten introducirnos en la relación que existe entre el discurso médico y su concepción del cuerpo femenino.

No es nuestra intención hacer una historia de la medicina, en el sentido lineal del término, ni tampoco podemos, por nuestra falta de pericia, comprender a cabalidad todas las recomendaciones farmacéuticas propuestas o el sentido práctico de todas ellas. En ese caso estaríamos, tal vez, sólo reconstruyendo el tratamiento médico propuesto y esa no es nuestra intención.

Partimos de algunas premisas que nos servirán de base para la reflexión, que provienen de los diversos trabajos dedicados al tema en las últimas décadas. En primer lugar, queda en evidencia que los siglos XVII y XVIII fueron testigos del gran cambio ocurrido en la ciencia médica. Desligándose de explicaciones teológicas, los científicos de la época se dedicaron a renovar las bases de su práctica, especialmente a partir del nuevo auge anatómico y de las escuelas que se generaron. Desde esta perspectiva resulta interesante no sólo seguir la evolución de la ciencia médica como tal, es decir, las escuelas, medicamentos y técnicas, sino - y este es nuestro caso- determinar qué imágenes de la enfermedad y del cuerpo se encuentran detrás de estos cambios. En ese sentido, un primer objetivo de nuestro trabajo es explicitar dichas imágenes en estos dos informes médicos. Una

3 No tenemos referencias de José de Figueroa, pero de Aime Jacques Alexander Goujard Bonpland (1773-1858) existe bastante información. Nació en Francia y acompañó a Alejandro de Humboldt en su expedición a América; el ilustre alemán lo conoció en París donde Bonpland ya gozaba de buena fama, incluso él se encargó de redactar la parte dedicada a la botánica en la obra del alemán. Su informe médico está fechado en Santa, 6 de Septiembre de 1802. Esta localidad se encuentra a mitad del camino entre Lima y la ciudad de Trujillo en el norte del Perú. Según el itinerario del viaje, los científicos entraron al territorio del virreinato peruano en agosto de 1802 y en septiembre estaban visitando las minas de Hualgayoc, bastante lejos de Santa. Pasaría por esa zona probablemente a mediados de octubre, así que no coincide con la fecha del documento. Es difícil explicar la discordancia, aunque resulta poco probable la invención total del documento, pues Humboldt y Bonpland estuvieron en Lima entre el 23 de octubre y el 5 de diciembre, incluso llegaron a trabar amistad con el Dr. Hipólito Unanue, de manera que debe haber estado fresca en la memoria de los médicos la visita de los citados personajes. Minguet, Charles: Alejandro de Humboldt historiador y geógrafo de la América española (1794-1804), 2 Ts., México, Universidad Nacional Autónoma de México, 1985, T. I, págs. 61 y 202-206; y Ortega y Medina, Juan A.: "Estudio preliminar", en Humboldt, Alejandro de: Ensayo político sobre el Reino de la Nueva España. México, Porrúa, 1991, págs. I-CLXXV. 
cuestión que se comenzará a notar es la determinación de las enfermedades típicamente femeninas, explicables por las características de su fisiología, específicamente provenientes del útero. Esta nueva forma de jerarquizar a hombres y mujeres tiene implicaciones políticas, pues la exclusión de la mujer del espacio público se fundamentará en esta "realidad" fisiológica.

En segundo lugar, los trabajos dedicados al tema han enfatizado que la renovación científica, al generar innovaciones sobre la concepción del morbo, del cuerpo masculino y femenino, modificó las terapias aplicables y los comportamientos que definían lo sano de lo no-sano. ${ }^{4}$ De allí que nuestro segundo objetivo sea explicar el sentido que tienen las terapias que se sugieren a María Cabrera. Estas prácticas nos muestran la influencia de las nuevas teorías científicas, especialmente de las teorías mecanicistas. Se puede agregar en este punto que, mientras estos cambios ocurrían fundamentalmente en el seno de la cultura occidental, vale la pena preguntarse si afectaron a la América hispana y por ende a la medicina que se practicaba en Lima hacia principios del siglo XIX.

Resumiendo estos objetivos, nuestra tarea sería de-construir la imagen del cuerpo - en este caso femenino- que se encuentra detrás del diagnóstico médico, la serie de prejuicios que los facultativos de la época tenían y que se interconectaban tanto con la descripción de los síntomas de la enfermedad como con las terapias propuestas.

Finalmente, también queremos mostrar, a modo de ejercicio, lo útil que resulta este tipo de fuentes en el estudio de cómo se construyeron las diferencias entre hombres y mujeres hacia finales de la Colonia. La ilustración, con su discurso modernizador, estableció nuevas pautas para el comportamiento femenino; la educación, el rol de madre y de ama de casa, fueron afectados por este nuevo pensamiento. La mujer accede $-\mathrm{y}$ se promueve- a la educación y a las reuniones en salones literarios, pero es de alguna manera recluida en el espacio privado. ${ }^{5}$ Esto ha sido estudiado especialmente a partir de los textos literarios, los manuales religiosos, sobretodo, a partir de ese maravilloso esfuerzo editorial llamado el Mercurio Peruano. Pensamos que resulta importante acercarse a estos materiales que

4 El clásico en la materia sigue siendo Foucault, Michel: El nacimiento de la clínica. Una arqueología de la mirada médica, México, Siglo XXI, 1978. Para las diversas escuelas médicas puede verse Cunningham, Andrew: "Medicine to Calm the Mind: Boerhaave's Medical System, and Why it Was Adopted in Edinburgh", en Cunningham, Andrew y Roger French (eds.): The Medical Enlightenment of the Eighteenth Century, New York, Cambridge University Press, 1990, págs.40-66.

5 Perspectiva que se puede notar en los diversos artículos publicados en Zegarra, Margarita (comp.): Mujeres y género en la historia del Perú, Lima, Cendoc-Mujer, 1999. 
ofrecen tal vez el elemento básico: la visión del cuerpo, sobre el que se sustenta la nueva política que se aplica. En ese sentido, este trabajo sólo quiere abrir una brecha nueva, que esperamos pueda ser transitada por estudios posteriores. El cuerpo es la realidad sobre la que se aplica la política, sobre él se sustenta una visión particular de la sociedad y en esa interacción se expresan diversas categorías culturales con las que las sociedades se identifican. ${ }^{6}$ La enfermedad resulta el espacio privilegiado para llegar a esa realidad material y cultural que es el cuerpo, porque la enfermedad, como es conocido, no es sólo una cuestión somática; en ella influye la construcción social de lo que se considera enfermedad y cómo debe comportarse el enfermo dentro de ese rol elaborado por la comunidad. Y esto a través o a pesar del enfermo mismo, cuyo cuerpo se interpone entre la enfermedad (que no se ve como tal) y el médico.?

Podemos pasar revista, de manera somera, a la estructura que tienen ambos diagnósticos. ${ }^{8}$ En términos generales se puede afirmar que cuentan con tres partes. En una primera, mucho más amplia en el caso del médico Figueroa (anexo n. ${ }^{\circ} 1$ ), se vierten conceptos acerca de la enfermedad y la mujer. En una segunda, ambos textos describirán los síntomas que definen el morbo a tratar y, finalmente, en la tercera sección dan una serie de recomendaciones a seguir. Esta última parte es la más amplia en ambos textos, razón por la cual intentaremos contextualizar algunas —las que nos parecen especialmente importantes- de las recomendaciones médicas.

\section{Enfermedad y cuerpo femeznino: la melancolía}

Dice el médico Bonpland: "las enfermedades que acontecen a las partes de la generación son las que más afectan a la imaginación y debilitan

6 Mannarelli, María Emma: "Cuerpo femenino y discurso médico", en Márgenes, IX-15, Lima, 1996, pág..73-99. Anotemos, además, que en términos de investigación el cuerpo también es el lugar de encuentro interdisciplinario entre historiadores, antropólogos, sociólogos, lingüistas, etc.

7 Una definición tentativa - y provisional- de la enfermedad puede ser el conjunto de condiciones que juzgadas por una cultura o sociedad son tenidas por dolorosas e invalidantes para el individuo. Jackson, Stanley W.: Historia de la melancolía y la depresión. Desde los tiempos hipocráticos a la época moderna, Madrid: Turner, 1986, pág. 23. Para la comunidad y el rol del enfermo véase Douglas, Mary: Estilos de pensar, Barcelona, Gedisa, 1998, págs. 40, 41 y 50; y para la relación enfermo-enfermedad Revel, Jacques y Jean-Pierre Peter. "El cuerpo. El hombre enfermo y su historia", en Le Goff, Jacques y Pierre Nora: Hacer la historia. III-Objetos nuevos, Barcelona, Laia, 1980, págs.173-195.

8 Por considerar la singularidad de ambos textos los reproducimos como anexos. En el cuerpo del texto no daremos ninguna referencia a los documentos, pues todas ellas se pueden cotejar directamente en la reproducción anexa. 
con lentitud pero con más tenacidad al sistema general que necesita organisación"; mientras Figueroa sostiene que "uno de los motivos que ha causado grandes desórdenes en la economía animal ha sido siempre la imaginación vehemente. Sus progresos se han extendido hasta el punto de creer por verdaderas unas enfermedades simuladas. El sexo femenino, digo el bello sexo, es mucho más susceptible de estos padecimientos, pues las más pequeñas dolencias las preocupan y les hace caer en un entuciasmo". En ambos casos se plantea la relación entre cuerpo, enfermedad e imaginario femenino. ${ }^{9}$ La mujer estaría definida por su fuerte imaginación, la misma que la lleva a amplificar sus males o a simularlos..$^{10}$ Aunque dicho así no queda del todo claro, veremos que esta concepción tiene que ver con la idea del cuerpo femenino desde el punto de vista médico.

Podría parecer que entre el conocimiento científico y la imagen que se genera la sociedad acerca de las personas no existen demasiados puntos de contacto; sobre todo si estamos pensando en la hiper-especialización actual, que produce textos médicos destinados a un público especializado y minoritario. Pero por lo menos hasta el siglo XIX este saber estuvo dirigido no sólo a los especialistas, sino a un conjunto de personas muy variado: comadronas, médicos, flebotómicos, e incluso a mujeres y personas de juicio en general. Por esta razón no se puede negar la importancia que pudo tener este discurso en los comportamientos sociales y especialmente en la forma de explicarlos y decodificarlos en un momento determinado. ${ }^{11}$ Hasta el siglo XVII el médico tenía como función preservar a la mujer y cuidar su perfección estética; a partir del siglo XVIII, cuando se reconoce una especificidad de la mujer y una anatomía distinta a la del hombre, se generan patologías, higiene y hasta terapéuticas dirigidas exclusivamente a la mujer. ${ }^{12}$

Entonces, es importante determinar las características básicas que el conocimiento de la época ofrecía acerca de la identidad de las personas. Y quién mejor que Hipólito Unanue (1755-1833) para proporcionarnos

9 En el caso de las mujeres embarazadas su imaginación era considerada muy activa, de allí la influencia que los antojos podían tener sobre el feto. Así opinaba otro médico limeño, Cosme Bueno, en el siglo XVII. Lastres, Juan B.: Historia de la medicina peruana, 3 Ts., Lima, Imprenta Santa María, 1951, T. II, pág. 216.

10 La melancolía fue definida principalmente como el estado de ánimo en que primaba el miedo y la tristeza. Jackson, Stanley: Historia de la melancolía... pág.25

11 Berriot-Salvadore, Evelyne: "El discurso de la medicina y la ciencia”, en Duby, Georges y Michelle Perrot: Historia de las mujeres en Occidente, Madrid, Taurus, 1993, T. VI, págs. 109-151.

12 Ibídem, pág. 142. 
información al respecto. ${ }^{13}$ En 1806 publicó en Lima una de sus obras más aclamada: "Observaciones sobre el clima de Lima y sus influencias en los seres organizados, en especial el hombre"; libro reeditado en Madrid en 1815 y reimpreso en Lima en 1874. En ella Unanue trató de explicar, siguiendo la renovada influencia de Hipócrates "re-descubierto" por Sydenham y Boeerhave, ${ }^{14}$ en qué aspectos específicos de las personas se podía encontrar la influencia del clima y de la geografía.

La humedad limeña, que quitaba elasticidad al aire, impide la firme unión de los elementos que componen las partes sólidas del cuerpo humano, la sangre no circula, se acumula la bilis, los músculos se abaten y se debilitan. De allí que "la pereza sea un vicio inherente a los moradores de estos climas. El cuerpo enervado sólo desea el reposo y los placeres". ${ }^{15}$ El médico debe tratar de controlar la influencia funesta de estos rasgos, de allí que tenga sentido su obra pues él establece medidas terapéuticas a tomar para moderar estos hechos. ${ }^{16}$

Así, el americano pierde en vigor lo que gana en imaginación y comparación. Unanue no acepta la inferioridad del habitante limeño, sólo establece que es más propenso a "percibir con rapidez las imágenes de los objetos, sus relaciones y cualidades". La facilidad de expresión del indígena americano, su habilidad en la escultura, pintura, son hechos que comprueban estas ideas. ${ }^{17}$

Hasta aquí parece existir poca relación entre este punto y el discurso médico, pero el mismo Unanue se encarga de establecerla. Sostiene que la vinculación entre los objetos exteriores, nuestra percepción y el alma es directa:

la percepción que tenemos de los objetos proviene de la exactitud con que los órganos externos transmiten a nuestra alma las imágenes. Estas imágenes, no son, como vulgarmente opinan los lógicos, pinturas hechas en los órganos exteriores; son modificaciones de los extremos de los nervios, que expresan al alma los objetos que los

13 Afamado científico y médico peruano, profesor de anatomía, fundador del Anfiteatro Anatómico y de la Escuela de Medicina de San Fernando.

14 Cunningham, Andrew: "Medicine to Calm the Mind..."

15 Unanue, José Hipólito: Obras científicas y literarias, 2 Ts. Lima, Consultoría y Equipamentos Médicos, 1975, T.I, págs. 67-68

16 La idea de moderación, relacionada con la sexualidad, tiene una larga historia. Aunque como señala Foucault no existen los mismos principios entre la filosofía clásica y el pensamiento cristiano, uno de los aspectos que se resalta en el período helenístico es el papel del discurso médico en el autocontrol del cuerpo, que será retomado en los siglos siguientes y en especial en el s.XVIII. Foucault, Michel: Historia de la sexualidad. 3 La inquietud de sí, México, Siglo XXI, 1997, págs. 94-136.

17 Unanue, José Hipólito: Obras científicas... T. I, págs. 77-78. 
afectan; son unas contracciones activas que variando la figura y posición respectivas de las fibras nerviosas, sirven de lenguaje entre los entes materiales y el ser inmaterial del hombre. ${ }^{18}$

Es decir, lo que uno ve afecta a nuestro interior. Si esta es la relación general, en el caso de la mujer el tema es más importante. El médico Unanue establece que esta propiedad de los nervios de ser movibles y sensibles a las sensaciones puede ocasionar fácilmente excitaciones y convulsiones. La prueba era su propia difunta esposa, quien padeció de histeria según su diagnóstico; ella era capaz de ver durante la noche dado que cuando la aquejaba la citada enfermedad sus nervios se ultra-sensibilizaban. ${ }^{19}$ Anotemos: la histeria produce un estado de hiper-sensibilidad que afecta al alma y, por ende, daña al cuerpo. ${ }^{20}$

José de Figueroa resulta más explícito en esta relación. Si la mujer no puede conservar su belleza ni cumplir con su rol habitual de ama de casa y esposa, estos son síntomas inequívocos de la enfermedad, agravados por la propia percepción de la mujer:

esto lo motiva ya su poco padecimiento, ya el creerse ineptas para los quehaceres domésticos, ya que se concideran desgraciadas por considerar se descompaginará su hermosura y que no hallarán remedio para restaurarse. Estas y otras meditaciones fúnebres las ponen a las infelices en un estado de desesperación y abandono, que aquello que se podía remediar por un leve socorro del arte, se hace una enfermedad crónica difícil de extirparla. El encojimiento de ánimo en este sexo, su pudor, señoría, que tienen para manifestarse a un profesor luego que se ven acometidas de alguna enfermedad en las partes pudendas, hace nada menos que el incremento de sus males: el caso presente me lo caracteriza. (El subrayado es nuestro).

Este discurso médico establece los parámetros de la identidad femenina: bella, pudorosa, débil de ánimo y ama de casa. No se menciona en este párrafo directamente el ser esposa, pero a lo largo del documento es evidente que un tema importante era la imposibilidad de cumplir con el débito matrimonial. Esta visión no es única de Figueroa. Nuevamente Unanue también nos brinda información al respecto; para él la mujer debería ser, según el clima limeño, de "facciones delicadas, de expresión tierna,

18 Ibídem.

19 Ibídem, pág. 79.

20 Margarita Zegarra ha mostrado que en la construcción del estereotipo ilustrado de la mujer como madre se operó, al mismo tiempo, un proceso por el cual su condición física —que pronto la podía llevar a la histeria - la hacía recluirse en la paz del hogar. "La construcción de la madre y de la familia sentimental. Una visión del tema a través del Mercurio Peruano", Histórica, XXV, 1, Lima, 2001, págs. 161-207. 
ojos negros con pupila rasgada, animados de fuego y de sensibilidad; caracteres de un cuerpo endeble, pero electrisado". ${ }^{21}$ Es decir, bella, de cuerpo débil, que expresa sensualidad de manera recatada en la mirada, la misma que expresa la energía interna.22 La debilidad de la mujer es producto de su natural melancolía, la que produce "la anestesia o indiferencia para todo lo relativo a la sociedad". ${ }^{23}$ Este mal es producto de una fragilidad corporal, que se excita "a la vista de los túmulos y de las ruinas que nos recuerdan lo efímero de la vida; y a presencia de los grandes lagos, riscos y precipicios, porque nos consideramos sin fuerzas para salvar el peligro si cayéramos en ellas". ${ }^{24}$ (Nótese la relación entre observar ruinas y la mujer auto-contemplando su mal). El lugar central de este mal es el estómago y los órganos de la digestión, ${ }^{25}$ afecciones que en el caso de las mujeres se pueden encontrar de manera más frecuente. ${ }^{26}$ Además, Lima es el lugar, según Unanue, donde se desarrollan muchos males gástricos y es la mujer quien mayormente los sufre:

las mujeres, en especial, las padecen de tantos y tan diferentes modos, que después de haber registrado cuánto se ha escrito sobre esta enfermedad y aplicado sus remedios, quedé convencido de que era un Proteo, por lo común superior a las fuerzas del arte, y que sólo cedía a la templanza, el trabajo corporal y a la tranquilidad de espíritu. ${ }^{27}$

Es decir sólo cede a indicaciones médicas, puesto que los galenos recomiendan este tipo de vida a las mujeres. Además, esto está relacionado con el flujo menstrual, puesto que si se sufre de estos males no hay una buena circulación, se retienen los líquidos y se producen enfermedades que atormentan a las mujeres, "especialmente en el útero, en donde no hay el recurso del cuchillo, como en los pechos y labios"; principalmente, una vez más, por el problema del pudor femenino: "es muy vergonzoso y humillante a las pacientes" ${ }^{28}$

21 Unanue, José Hipólito: Obras científicas... pág. 68.

22 Véase también Mariátegui, Javier: El Mercurio Peruano y la medicina, Lima, Fondo Editorial Universidad Peruana Cayetano Heredia.

23 Unanue, José Hipólito: Obras científicas..., T.I, pág. 100.

24 Ibídem, pág. 99.

25 Unanue dice: "los órganos de la digestión son el sitio principal de esta debilidad; por eso los antiguos filósofos colocaban en la boca superior del estómago el asiento del alma” (ibídem).

26 Médicos como Sydenham creían en la relación existente entre la melancolía y las afecciones estomacales, tradición que provenía de la antigüedad clásica. Jackson, Stanley: Historia de la melancolía..., págs. 255-283.

27 Unanue, José Hipólito: Obras científicas..., T.I, pág. 85.

28 Ibídem. 
El conocimiento médico refuerza la construcción de los roles de hombre y mujer. El siglo XVIII les otorga una nueva base científica sobre la que se cimentará la política acerca de los sexos..$^{29}$ Es, además, una muestra de poder de parte de los hombres acerca de las mujeres. Ese otro, altamente escurridizo y difícil de catalogar, se muestra a partir del Renacimiento sistemáticamente despojado de secretos. Ese es el sentido de las ilustraciones que acompañan las bellas ediciones de los anatomistas. En una mezcla de erotismo y ciencia, el cuerpo de la mujer se muestra a los ojos de quienes deseen conocerlo y - sobre todo - aprender a controlarlo a partir de este conocimiento..$^{30} \mathrm{~A}$ pesar de ello, el médico tendrá que lidiar con el pudor "natural" de la mujer, para llegar a conocer tanto su cuerpo como para diagnosticar adecuadamente la enfermedad que la aqueja. Como anota Radkau, este pudor resulta, a la luz de los descubrimientos médicos del XVIII y XIX, una de las características que define a la mujer, al mismo tiempo que constituye una barrera para la curiosidad científica. ${ }^{31}$

Es sólo a mediados del siglo XVIII cuando un esqueleto femenino se muestra en los libros de anatomía; hasta ese momento la única estructura que mostraba el cuerpo humano era la masculina. ${ }^{32} \mathrm{~A}$ partir de la ilustración la ciencia médica intentó encontrar - y lo logró- en el interior o exterior del cuerpo humano algo específico que definiera al hombre y a la mujer. Mientras en el Renacimiento el cuerpo ratificaba, más que creaba, la diferencia entre los sexos. ${ }^{33}$

Por esta razón el discurso médico, por muy neutro que pueda parecer, sobre todo a partir del siglo XVIII ofrece una especial relación con el discurso político. La aparición de la clínica y de un saber altamente especializado, que muestra "las verdades esenciales", más la reglamentación a la

29 Cabe añadir que el argumento de la melancolía para excluir a las mujeres del espacio público es también aplicado a los indios del Perú. Unanue afirma que los indios son solitarios, su música es melancólica e incluso podían llegar al suicidio (ibídem, pág. 101). La templanza era, desde el pensamiento clásico, el vínculo entre la política y el ciudadano, el autocontrol era el equivalente a la habilidad de poder gobernar la polis. Foucault, Michel: Historia de la sexualidad. 2 El uso de los placeres, México, Siglo XXI, 1988, págs. 34-91.

30 Laqueur, Thomas W.: La construcción del sexo. Cuerpo y género desde los griegos hasta Freud, Madrid: Ediciones Cátedra, 1994, págs. 139-140.

31 Radkau, Verena: "Los médicos (se) crean una imagen: mujeres y médicos en la prensa mexicana del siglo XIX” en Gonzalbo Aizpuru, Pilar (Ed.) Género, familia y mentalidades en América Latina. San Juan de Puerto Rico, Universidad de Puerto Rico, 1997, págs.127-160.

32 Laquer, Thomas W.: "Amor veneris, vel dulcedo appeletur" en Feher, Michel, Ramona Naddaff y Nadia Tazi: Fragmentos para una historia del cuerpo humano, 3 Ts., Madrid, Taurus, 1990, T. III, págs. 91-131

33 Laquer, Thomas: La construcción del sexo..., págs. 234-235. 
que la práctica médica se verá forzada a partir del XVIII, evidencian los innegables vínculos entre el saber y la política. ${ }^{34} \mathrm{El}$ conocimiento médico se convierte en la base fundamental para la organización social. La mujer es alejada del espacio público en razón de su anatomía. La debilidad de sus órganos y su tendencia nerviosa justificarán de una nueva manera su exclusión de los espacios políticos; el discurso ilustrado liberal de igualdad de derechos y eliminación de las diferencias tradicionales encuentra un nuevo anclaje. Las nuevas anatomía y fisiología concurren en favor de las diferencias sociales, ese es el límite del discurso.

Este proceso se inició en el Renacimiento. Paracelso, fundador de la escuela iatroquímica, definía la fisiología femenina a partir del útero. Sostenía que "la mujer está constituida por la necesidad de este órgano, pues sólo existe por este órgano". ${ }^{35}$ Se le atribuía toda una personalidad propia al útero; se le consideraba irascible y fuente de una enfermedad absolutamente femenina: la histeria. ${ }^{36}$ Esta era descrita a partir de los movimientos erráticos del útero, el cual provocaba sofocación de la matriz. La misma definición sugiere "furor uterino", causado por vapores venenosos fomentados por la matriz, los cuales se dirigen al cerebro por las arterias y nervios que se suponía conectaban al órgano. Se curaba cambiando el modo de vida, evitando la retención de materia seminal, llevando una vida prudente y - especialmente - tranquilizando al útero por medio del matrimonio y el embarazo. ${ }^{37}$ Es el útero desenfrenado, que se movía, a pesar de que las investigaciones de la época habían demostrado la imposibilidad física de tal desplazamiento; prueba de que los anatomistas del Renacimiento no veían lo que nosotros vemos en el cuerpo humano.$^{38}$ Esto llevó, hacia el último tercio del siglo XIX, a "corregir" el comportamiento inadecuado de una mujer a través de la ovariotomía de órganos sanos. ${ }^{39}$

Por esta razón el médico, especialmente a partir del siglo XVIII, reemplazará poco a poco el rol que antes tenía el sacerdote. El discurso médico finalmente ofrece una identidad y finalidad a los seres, una explicación de su comportamiento tanto en la salud como en la enfermedad.

34 Foucault, Michel: El nacimiento de la clínica..., págs. 72-75.

35 Berriot-Salvadore, Evelyne: "El discurso de la medicina...", pág. 120.

36 Desde el siglo XVII dominó la concepción del útero como definitorio del comportamiento femenino. Radkaud, Verena: "Los médicos (se) crean una imagen...”, pág. 135.

37 Berriot-Salvadore, Evelyne: "El discurso de la medicina...”, pág. 124. Se decía, además, que era una enfermedad de la ociosidad, en clara alusión a la inactividad del útero.

38 Laqueur, Thomas: La construcción del sexo..., pág. 198.

39 Ibídem, pág. 300-302 y Radkaud, Verena: “Los médicos (se) crean una imagen...”, pág. 136. 
Ambos son garantes del orden social y de la estabilidad de la pareja, los dos se encargan del cuerpo amenazado por el dolor y la muerte, y, en último caso, deberían ofrecer compasión frente al sufrimiento humano. ${ }^{40}$

Entonces, la mujer definida desde el punto de vista del discurso médico está marcada por la debilidad de su cuerpo, ratificada a partir de las investigaciones anatómicas acerca de sus órganos genitales. Esto se muestra de manera muy clara con las investigaciones de Freud, quien encontró los fundamentos biológicos del género; ${ }^{41}$ pero ya desde el siglo XVIII, al investigar anatómicamente el útero de la mujer se determinó que la feminidad residía en él. No sólo por ser el receptáculo del nuevo ser, sino por las implicaciones que tiene éste en cuanto a sus conexiones con el cerebro y nervios de la mujer, influyendo de manera decisiva en su comportamiento. ${ }^{42}$

\section{Los síntomas: la sangre y el frío}

En el caso aquí estudiado, ambos médicos se dedican a describir el estado de la enferma. Aunque no se puede afirmar que la hayan tenido delante, tampoco parece ser necesario dentro del esquema médico clasificatorio de la época. Los síntomas muestran una clase de enfermedad que ya se encuentra codificada, y el médico debe tratar de determinarla a partir de esos rasgos visibles. En ambos diagnósticos se habla de leucorrea, flujo vaginal de color blanquecino que desciende en lugar del normal flujo menstrual. El médico Bonpland interpreta este síntoma de acuerdo a un cuadro nosológico, deduciendo la debilidad del útero, falta de menstruación y debilitamiento corporal. Figueroa sostiene que este hecho hace perder la elasticidad del órgano ${ }^{43}$ y "no le permite reacerse en quanto a los estragos que hacen los placeres de Venus". Además, la enferma corre el riesgo de que este mal, por ahora benigno, se convierta en maligno por el contacto con algún galicado. Resumiendo, ambos médicos consideran que este flujo y la ausencia de menstruación son signos de algo mayor: la debilidad del útero y su falta de elasticidad, causantes del deterioro visible y del

\footnotetext{
40 Berriot-Salvadore, Evelyne: "El discurso de la medicina...”, págs. 147-148.

41 Laqueur, Thomas: "Amor Veneris..." pág. 93.

42 Berriot-Salvadore, Evelyne: "El discurso de la medicina...”, pág. 150.

43 Se relacionó durante mucho tiempo al útero con un músculo, de allí que la descripción hable de elasticidad.
} 
cambio en el comportamiento de la enferma. Bonpland dice que la palidez del rostro, el decaimiento del cuerpo y "sobre todo la debilidad del ánimo y la anafrodicia ${ }^{44}$ que padece la hacen digna de compasión y piden los mas poderosos y prontos auxilios".

En el siglo XVIII, surgen la medicina y la clínica moderna. ${ }^{45}$ Esta nueva mirada tratará de establecer causas y explicaciones empíricas de la enfermedad; se fija en las regularidades para construir un sistema racional sobre la enfermedad. A partir del resurgimiento de la escuela empírica, que establecía la conveniencia de que el médico se guíe principalmente por sus propias observaciones y experiencias, la medicina se fijó especialmente en las constantes que permitían explicar la aparición y el desarrollo de las enfermedades. Por esta razón la escuela hipocrática también fue retomada, especialmente a partir de su preocupación por la influencia del clima en los seres humanos. ${ }^{46}$

Es en el siglo XVII cuando el saber médico se racionaliza, especialmente a partir de Thomás Sydenham (1624-1689), el cual retomó la ciencia hipocrática, estudiando la enfermedad en el enfermo mismo. ${ }^{47}$ Este médico redefinió el objetivo de la práctica médica, que se debería dedicar a una historia natural de la enfermedad, es decir una descripción gráfica y natural de ella, para encontrar una praxis o método relacionado. De esta manera se podría establecer una clasificación adecuada, para que el médico al observar una enfermedad pudiera "prescindir de cualquier hipótesis filosófica que haya ocupado previamente la mente... deben anotarse los fenómenos claros y naturales de la enfermedad y solo éstos". ${ }^{48}$ La idea de Sydenham era que el médico pudiera reflejar con exactitud de pintor las características propias de cada enfermedad, para poder establecer el conjunto de signos observables por los sentidos. Se trata de establecer "formas procesales típicas, abstractas y universales, perceptibles sensorialmente e independientes del propio individuo enfermo". ${ }^{49} \mathrm{El}$ enfermo es solo un

44 La palabra proviene de aphrodisia (actos de Afrodita), que son los gestos que buscan el placer. La negación (anafrodisia) sería el rechazo o la falta de apetito sexual. Foucault, Michel: Historia de la sexualidad. 2 El uso..., págs. 34-91.

45 Foucault, Michel: El nacimiento de la clínica..., pág. 5.

46 Ibídem, pág. 54.

47 Babini, José: Historia de la medicina, Barcelona, Gedisa, 1980, pág. 102.

48 Sánchez-González, Miguel: "Especie morbosa y filosofía empirista en el siglo XVII", en Albarracín, Agustín (Coord.): Misterio y realidad. Estudios sobre la enfermedad humana, Madrid, Centro de Estudios Históricos, Consejo Superior de Investigaciones Científicas, 1988, págs. 159-176.

49 Ibídem, pág. 165. 
medio para llegar a esa realidad, de la cual vemos sus efectos pero no sabemos sus causas. La enfermedad revela sus secretos al mostrar en su regularidad, e independientemente de quien la sufra, la posibilidad de establecer una clasificación que guíe la práctica médica, autónoma incluso de las características propias del enfermo: "es preciso que el que describe una enfermedad tenga el cuidado de distinguir los síntomas que la acompañan necesariamente y que le son propios de los que no son sino accidentales y fortuitos, tales como los que dependen del temperamento y de la edad del enfermo"; como señala Foucault, el paciente es un hecho exterior, prácticamente aleatorio. ${ }^{50}$

La enfermedad no se define a partir del encuentro entre el enfermo y el médico, sino a partir de una serie de síntomas clasificados que se cruzan con otra serie sufrida por el enfermo. De allí también el interés de la medicina del XVIII en establecer lo que corresponde al hombre sano y lo "normal", oponiendo lo sano a lo mórbido. ${ }^{51}$

Por otro lado, la ciencia médica en Lima a lo largo del siglo XVIII sufrió un proceso de modernización que tuvo su período floreciente entre 1791 y $1806 .{ }^{52}$ Desde la creación de la cátedra de anatomía en 1791, la construcción del anfiteatro anatómico en 1792 y el funcionamiento de la escuela de medicina en 1808, se puede notar la influencia de las nuevas tendencias europeas. Autores como Boeerhave, Cullen, Sydenham, Vesalio, etc., son parte de la nueva enseñanza médica. Unanue definía la práctica de la medicina como la conservadora de la vida y destructora de las causas que impedían el ejercicio de las funciones. Lo primero se lograba a partir de la dieta y lo segundo con los remedios; enfatiza especialmente el tema de la dieta pues ésta permite al cuerpo recuperar su propia energía curativa. La medicina se funda en la observación puntual de los hechos, tratando de establecer en cada país la enfermedad dominante que determina a las demás. Esto permitirá clasificar los males y poder establecer el remedio más adecuado. De aquí se deriva que en Lima la causa principal de las enfermedades es el frío, el cual principalmente produce catarros y males estomacales. El frío bloquea los poros de la piel, debilita la acción de los vasos y entorpece el cuerpo..$^{53}$ Para la clasificación adecuada de las enfer-

50 Foucault, Michel. El nacimiento de la clínica... pág. 23.

51 Ibídem, págs. 54, 61-62.

52 Lastres, Juan B.: Historia de la medicina..., T.II, pág. 272 y Clément, Jean Pierre: "Decadencia y restauración de la medicina peruana a fines del siglo XVIII", en Asclepio. Revista de Historia de la Medicina y de la Ciencia, XXXV, Madrid, 1983, págs. 138-217.

53 Unanue, José Hipólito: Obras científicas..., T.I, págs. 125-127 y 162-164. 
medades, Unanue aconseja los sistemas de Cullen: historia, curación y observación de la enfermedad; ${ }^{54}$ también recomienda la escuela de Leyden y especialmente los trabajos de Boeerhave..$^{55}$

Por ello, el diagnóstico de Figueroa muestra los conocimientos médicos de la época. Al clasificar la enfermedad, explica la anafrodicia por el infarto de los ovarios, tubos falopianos y la arteria del útero. Los dos primeros fueron descubrimientos anatómicos, que eran ya conocidos en Lima especialmente a partir de la cátedra de anatomía. ${ }^{56}$

Regresemos al significado de los síntomas observados. ¿Cuál es la importancia de la falta de menstruación? Este asunto tiene dos aspectos importantes. Por un lado, significa evidentemente la imposibilidad individual de cumplir con los deberes del matrimonio y por ende ser incapaz para engendrar hijos. Por otro lado, se rompe un rasgo natural y definitorio de la identidad femenina. La falta de menstruación era considerada en extremo peligrosa. Un médico articulista del Mercurio Peruano sostenía que Hipócrates había descrito el caso de una mujer que dejó de menstruar, acto seguido le salió barba y vello por todo el cuerpo. ${ }^{57}$

La sangre corresponde al mismo tiempo a un humor y al líquido que circula al interior del cuerpo humano. ${ }^{58}$ Desde tiempos antiguos se reconoció que era el fluido básico para la concepción de la vida en el cuerpo femenino. Su acumulación excesiva en cualquier persona era considerada nociva y se buscaba eliminarla periódicamente por medio de sangrías. ${ }^{59} \mathrm{La}$ sangre, como fluido, expresaba el carácter de una persona. Si predominaba la bilis negra en ella y por lo tanto teñía de negro el fluido, la personalidad sería melancólica. En principio el fluido sanguíneo es caliente y húmedo; mientras que la bilis negra expresa frialdad y sequedad, bases del compor-

54 Ibídem, pág. 263.

55 Ibídem, T.III, pág. 83.

56 Lastres, Juan B.: Historia de la medicina..., T.I, pág. 322.

57 Ganarrilla, Joseph Torpas. [Joseph Pastor de Larrinaga]: "Segunda disertación en que se trata si una muger se puede convertir en hombre", en Mercurio Peruano, V, 156-157, 1792, Lima, Edición Facsimilar Biblioteca Nacional del Perú, 1966, págs. 230-243.

58 Es interesante, como anota Pouchelle-Peter, que la teoría de los humores aún perdure hasta la actualidad, pues hasta hoy hablamos de "mal humor". Pouchelle-Peter, Marie Christine: "La enfermedad y sus representaciones: una ojeada sobre la persistencia", en Asclepio. Revista de Historia de la Medicina y de la Ciencia, XXXV, Madrid, 1983, págs.117-128.

59 El derramamiento de sangre como limpieza o curación podía estar relacionado con la muerte de Cristo, que purgó nuestros pecados a partir de su propio desangramiento. Walker Bynum, Caroline: "El cuerpo femenino y la práctica religiosa en la Baja Edad Media", en Feher, Michel, Ramona Naddaff y Nadia Tazi: Fragmentos para una historia del cuerpo humano, 3 Ts., Madrid, Taurus, 1990, T. I, págs. 163-225. 
tamiento melancólico. ${ }^{60}$ El calor diluye, el frío condensa la sangre; por esta razón, la sangría frena el calor y debe aplicarse con cuidado.

El color peligroso en la sangre es el blanco, que muestra predominio de flema, y sujetos de complexión fría y húmeda en extremo. La falta de calor del hígado, dentro de la teoría galénica, estaría dejando sin "cocer" los alimentos y al fluido sanguíneo sin el suficiente calor, dejándolo "crudo". Esta mala digestión o mal régimen sería propio de aquellos sujetos que viven en la ociosidad y excediéndose en la comida o bebida. En este caso la sangría estaría contraindicada pues aumentaría el frío en la sangre. ${ }^{61}$

La menstruación sería el proceso natural por el cual las mujeres expulsan el exceso de sangre que poseen. Bajo esta óptica se explica por qué las mujeres embarazadas o madres lactantes no menstrúan, pues el exceso se convierte en alimento para el feto o leche para el recién nacido. ${ }^{62} \mathrm{Si}$ un proceso "natural" no ocurría, se temía que la naturaleza encontrase diversas salidas a ese exceso. Un médico sostenía que a algunas mujeres la sangre se les escapaba por los ojos, orejas, vómitos, etc. ${ }^{63}$

El temperamento de la mujer, como ser "imperfecto", en el cual prima su frialdad y humedad, ocasiona que la falta de calor no transforme todo el alimento en sangre. Se produce así un elemento residual, eliminado a partir de la menstruación o cualquiera de los otros procesos mencionados. ${ }^{64}$ Se hace necesario que la mujer controle con mayor cuidado que el hombre su régimen alimenticio, no caiga en excesos y lleve una existencia sosegada, evitando la pérdida inútil de calor. En caso contrario, el descontrol puede provocar una irregularidad en el periodo o la aparición del "flujo blanco", síntoma inequívoco de la grave pérdida de calor del cuerpo. ${ }^{65}$ Es decir, esta secreción estaría mostrando el otro aspecto de la identidad femenina: su falta de calor y su complexión fría. ${ }^{66}$ De allí la preocupación de ambos médicos en la enfermedad que aqueja a María Cabrera.

60 Gil-Sotres, Pedro: "Sangre y patología en la medicina bajomedieval: el substrato material de la flebotomía”, en Albarracín, Agustín: Misterio y realidad... págs.73-104. Además, la melancolía da a la sangre un olor ácido, mientras que el mal olor expresa putrefacción y el olor amargo exceso de bilis (ibídem, págs. 90-91).

61 Ibídem, pág. 89.

62 Laqueur, Thomas: La construcción del sexo..., pág. 74.

63 Ibídem, pág.189.

64 Berriot-Salvadore, Evelyne: "El discurso de la medicina...”, pág. 114

65 Laqueur, Thomas: La construcción del sexo..., pág. 192. Se agrega, además, una explicación distinta del "flujo blanco".

66 Sennet, Richard: Carne y piedra. El cuerpo y la ciudad en la civilización occidental, Madrid, Alianza Editorial, 1997, pág. 74. 


\section{Terapias: devolviendo la elasticidad y moderando el comportamiento}

Hasta aquí, más o menos, hemos intentado decodificar la visión del cuerpo femenino que está detrás de los diagnósticos. La tendencia a la melancolía y la excesiva frialdad-humedad de la mujer se encuentran detrás de la mirada de ambos médicos; las terapias propuestas resumen bastante bien ambas perspectivas. Destacaremos tres aspectos: el ejercicio, el cambio de aire junto a la dieta, el baño y el uso de la electricidad. Resaltemos que el objeto de estas prácticas será restaurar algo de calor a la enferma, para que de esta manera sus órganos internos recuperen su elasticidad y circulen adecuadamente los humores. Cabe destacar que la panacea universal de la medicina, la sangría, se encuentra ausente de ambas prescripciones. La razón es simple: si el flujo blanco es síntoma de falta de calor, la sangría agravaría la situación. ${ }^{67}$

\section{Movimiento}

Figueroa indica que "el paseo al campo y movimiento de la gestación y procurar ver todos aquellos objetos que embien al alma unas ideas agradables, pues en sentir de Hunter, hay mugeres que padecen este mal y luego que salen al campo les sesa y retorna quando regresan. La vida sedentaria disminuye la actividad de la circulación y la tristeza las aumenta". Bonpland es más específico: "hará diariamente, esto es por la mañana y por la tarde, exercicios moderados a pie y a caballo o en carruage y procurará por todos los medios posibles amenisar sus ideas dibirtiéndose para distraerse y olbidar si fuese posible su enfermedad". Ambos pensamientos coinciden en algo: efectuar movimientos del cuerpo y contemplar o hacer cosas agradables para olvidar la enfermedad.

Esto retoma un punto que ya hemos visto: la influencia de las imágenes en el funcionamiento de los órganos internos; pero es momento de agregar

67 No podemos hacer un análisis de las medicinas recomendadas, pues carecemos de estudios que nos ilustren las propiedades de la farmacopea colonial en Lima. Sólo podemos indicar, con relación a los medicamentos recetados en nuestro documento, que la yerbabuena era utilizada para el tratamiento de tumores, los eméticos eran antifebrífugos, la goma arábiga servía para disminuir el efecto irritante de los medicamentos y el alcanfor combatía calenturas e inflamaciones. Vidal Galache, Benicia: "La terapéutica hospitalaria del siglo XVIII: Drogas y otros recursos sanadores", Asclepio. Revista de Historia de la Medicina y de la Ciencia, XLIV, 2, Madrid, 1992, págs. 83-122. 
un elemento adicional: el cuerpo interpretado bajo las leyes de la mecánica. ${ }^{68}$ Esta forma de entender el problema del cuerpo fue, bajo la influencia de las ciencias físicas, concebirlo como una máquina, aplicando las leyes del movimiento y la mecánica de los cuerpos. Por ejemplo, considerar que el cuerpo humano es un juego de palancas a partir de las fibras y huesos. Los dientes son tenazas, el estómago un triturador, los pulmones fuelles, el corazón un resorte, los vasos tubos hidraúlicos, etc. ${ }^{69}$ Esta fue la llamada escuela iatromecánica. Aparentemente estas escuelas no fueron del todo rígidas, pues el médico holandés Heerman Boeerhave (1668-1758), desde su cátedra de la Universidad de Leiden y la clínica que dirigía, practicó un conocimiento claramente ecléctico. Era iatroquímico, iatromecánico e hipocrático. ${ }^{70}$

Unanue consideraba que las contracciones musculares provocaban estímulos en los nervios y estos, a su vez, daban origen a las imágenes que se proporcionaban al alma. ${ }^{71}$ Por ello el hombre que camina tiene más vida que el sedentario, quien goza de todos sus sentidos activos a los estímulos externos. El ejercicio permite la transpiración, la eliminación de los excesos, de allí la importancia que tiene éste en el caso de la mujer, pues la enferma que ha perdido la menstruación debe eliminar esa acumulación por otras vías. Unanue, coincidiendo con Bonpland, también recomienda que los ejercicios se realicen por la mañana y por la tarde; además, deben hacerse con el estómago descargado. ${ }^{72}$

\section{Aire puro y dieta}

Figueroa sugiere que la enferma se mude hacia una atmósfera limpia, lejos de emanaciones, tópico muy tratado en la época. ${ }^{73}$ Lima era considerada un lugar con aire de mala calidad; no era (o todavía no lo es) muy recomendable para la respiración, por la alta carga de humedad que posee. ${ }^{74}$ La respiración era concebida como combustión, bajo el "descubrimiento" de Priestley del aire flogístico y de-flogisticado, que en el proceso de res-

68 Estos principios también se aplicaron sobre las ciudades. Sennet, Richard: Carne y piedra..., págs. 273-278.

69 Babini, José: Historia de la medicina..., pág. 100.

70 Ibídem, pág. 117.

71 Unanue, José Hipólito: Obras científicas..., T. I., pág. 102.

72 Ibídem, págs. 119-120, 161-166.

73 Corbin, Alain: El perfume o el miasma. El olfato y lo imaginario social. Siglos XVIII y XIX. México, Fondo de Cultura Económica, 1987.

74 Unanue, José Hipólito: Obras científicas..., T.I, págs. 22-23. 
piración dejaba aire mefítico a su paso y si no se renovaba resultaba altamente nocivo. De allí la necesidad de que los enfermos cambien de aire, evitar que estén en cuartos estrechos y que de esa manera se consuma el aire vital. Unanue indica que el aire vital debe aplicarse en aquellas enfermedades que "proceden de debilidad, atonía o afofamiento", pues el aire tiene la virtud de estimular el calor. ${ }^{75}$ Justamente lo que Doña María necesitaba, según sus facultativos. En las enfermedades nerviosas el aire tiene el don de ejercer curaciones rápidas al cambiar el aire malsano de las ciudades por el aire puro del campo. La segunda mitad del siglo XVIII trajo una nueva preocupación por la vuelta a la naturaleza y el ideal de la vida campesina, recomendada en numerosas publicaciones dedicadas a difundir estos principios entre los estratos populares europeos. ${ }^{76}$

De allí la importancia de la dieta. Si el cuerpo femenino es de por sî carente de calor, debe generarse por intermedio del aire puro, pero también por medio de una adecuada alimentación. Bonpland indica que la enferma debe seguir un "régimen antiflogístico y tomará tres veces al día alimentos de fácil digestión en moderada cantidad, para de este modo restablecer las funciones del estómago debilitado... tendrá cuidado de mantener su vientre libre por medio de las sales neutras, etc.". Esto significa que la mujer deberá evitar comidas demasiado pesadas, que recarguen de calor el cuerpo, mientras éste no pueda procesar adecuadamente esos alimentos por su debilidad. Una comida prudente sumada a la tranquilidad y sueño regular, son las bases de la curación. ${ }^{77}$

\section{Baño y electricidad}

Veamos lo que dicen nuestros médicos:

Bonpland:

los baños fríos, la leche, las emulciones se usarán todo el tiempo de la curación... En el período abansado de esta enfermedad, todos estos remedios serían ineficaces sino hiban de par con la electrisidad, con este agente tan poderoso y que no conosieron

75 Ibídem, pág. 134.

76 González de Pablo, Angel: "La dietética para el hombre sano en el pensamiento médico del mundo moderno", Asclepio. Revista de Historia de la Medicina y de la Ciencia, XVII, 1, Madrid, págs. 69-117.

77 Ibídem, págs.103 y 116. 
nuestros padres, con este fluido admirable, único estimulante conocido en la medicina capas de restablecer el mobimiento y reanimar las partes inertes o muertas del cuerpo humano, Rovilley, Adams, [ilegible],Cavallo, Bertholon, Cullen y todos los médicos modernos recomiendan este imponderable remedio en la leucorrhea, ... La enferma se hará electrisar por un físico experto del modo siguiente: $1 .^{\circ}$ Tomará por la mañana sobre el ayslador un baño eléctrico de una hora y en este espacio de tiempo se le sacarán doscientas chispas. 2 . $^{\circ}$ Por la tarde resibirá treinta commociones y se la sacará igualmente doscientas chispas fuertes. Las commociones serán al principio fuertes, mas como las fricciones mercuriales la hacen mui sensibles se arreglará la intencidad sobre las fuerzas de la enferma.

Figueroa:

antes es necesario dar un baño de agua fría, para dar tono o reanimar a las partes que han caido en un estado de inerción [sic]... la electrisidad es muy oportuna respecto que da tono a las perdidas con la comoción [sic] que causa en el systema. No me detengo en sus prerrogativas por ser muy difusa esta materia y por que mi talento y conocimiento son muy escasos y porque la mayor parte de los médicos de este nuevo mundo no adoptan sus admirables virtudes por hallarse distantes de la verdad, aunque a pesar de las críticas y emulaciones vulgares sin razón ella prevalescerá pues sin embargo de su crítica ningún descubrimiento han hecho ha veneficio de la humanidad.

Aquí aparece una pequeña discrepancia. Figueroa parece un poco dubitativo frente a la posibilidad del uso de la electricidad. Puede ser que el temor se explique porque son los extranjeros quienes, como en este caso, han practicado o ejercen esta actividad, formando una competencia. Parece menos probable que exista una resistencia "tradicional" frente a la innovación; existen muchos puntos comunes entre la práctica de la medicina europea y peruana; de hecho, como veremos, el uso de la electricidad era conocido desde finales del XVIII.

Los médicos hipocráticos identificaron la humedad con la vida; así, los viejos eran tales por la pérdida de humedad..$^{78}$ Antes de los siglos XVIXVII el baño estaba relacionado más que con el acto de limpieza, con lo lúdico y la sociabilidad festiva. Los baños públicos eran lugares de transgresión del orden y de excesos, tradición que se acaba con el tránsito al mundo moderno. ${ }^{79}$ En el siglo XVII el baño aparece bajo su forma terapéutica. Se practica especialmente para rehumedecer el cuerpo después de una larga serie de sangrías; se debe tener especial cuidado en efectuarlo, purga e irrigación en la víspera, para evitar la infiltración excesiva del agua

78 Gil-Sotres, Pedro: "Sangre y patología...”, pág. 93.

79 Vigarello, Georges: Lo limpio y lo sucio. La higiene del cuerpo desde la Edad Media, Madrid, Alianza Editorial, 1991, pág. 51. 
(recuérdese que se considera a la piel de manera permeable), reposo e interrupción del baño a la presencia de cualquier malestar. En su mayor parte los baños, es decir las inmersiones, son efectuadas bajo tratamiento médico para purificar los humores.

En el siglo XVIII la inmersión es bastante más aceptada. Se cree que el flujo del agua ejerce una tensión favorable para el cuerpo humano, aunque no se abandonan los cuidados que ya se han mencionado. Al baño se le agrega frotación con aceites para mantener la flexibilidad de los nervios, para que la transpiración se vea facilitada, para que los humores circulen sin problemas en el cuerpo; especialmente el baño con agua caliente es recomendado para la circulación de los humores. El agua se concibe como una pequeña fuerza de choque, que por medio de ondas y vibraciones, movimientos y presiones, transmite esas fuerzas al cuerpo que lo recibe. $\mathrm{La}$ Facultad de Medicina de París lo aprueba, dado que considera su influencia mayor a la de un buen clima. ${ }^{80}$

Cada temperatura del agua tiene su peculiaridad terapéutica. El agua caliente, considerada más penetrante, llega a todas las partes del cuerpo y las estimula. El agua tibia tempera los calentamientos, calma los nervios y apacigua. El agua fría crea contracciones y recupera el vigor de los músculos al endurecerlos.

A partir de 1750 el baño era una experiencia principalmente terapéutica, mientras que desde 1760 se empiezan a resaltar las virtudes del agua fría. Se considera que es capaz de temperar, calmar las agitaciones excesivas (o exceso de calor), contrae los vasos sanguíneos que se encuentren peligrosamente dilatados y, finalmente, refuerza las partes astringiéndolas. Ayuda a la circulación de los humores y a la eliminación de los excesos. Es, como dice Vigarello, un símil de la moderación, comparable a la ropa prudente y la vida ordenada, rechazando la molicie y relajación representadas por el baño de agua tibia. Es la vuelta a la vida sencilla, idealizada por la burguesía francesa a partir de sus gustos neoclásicos. Lo contrario era la decadencia aristocrática, el lujo innecesario e improductivo. Por esta razón, la Academia de Ciencias de Francia propuso un artificio mecánico, que producía una corriente comparable a la de los ríos, cuyo baño se recomendaba altamente; este artefacto permitía tomar cómodos baños que agregaban a la presión benéfica del agua y del frío las ondas de choque tan recomendadas. ${ }^{81}$

80 Ibídem, págs. 26, 27, 38, 126 y 136.

81 Ibídem, págs. 129-159. 
Unanue considera que los baños fortalecen y limpian el cutis. De todos modos no deben tomarse ciertas precauciones antes de tomarlos, como bañarse en ayunas y con el cuerpo sin sudar; además, es especialmente recomendable en las enfermedades venéreas, aunque el docto limeño prefiere el baño tibio para los enfermos antes que el frío. ${ }^{82}$ Otro autor mencionaba que humedecer las partes del cuerpo era importante para mantener la juventud, tanto como limpiarse y purificarse por dentro, pues el agua era el principal disolvente de la naturaleza. ${ }^{83}$

En 1660 Otto Von Guericke creó la primera máquina que acumulaba electricidad por frotamiento. Consistía en una bola de azufre que giraba sobre un eje y que acumulaba gran cantidad de electricidad estática que se descargaba y cargaba casi indefinidamente. En 1745, en Leiden, sede de una de las más importantes escuelas de medicina, se inventó la "botella de Leiden", un vaso de vidrio forrado internamente de metal y atravesado por una varilla, que acumulaba gran cantidad de electricidad cargada por medio de una máquina. Este artefacto podía emitir descargas, similares a pequeños rayos, capaces de hacer pasar un mal rato a un hombre. ${ }^{84}$ Un poco más tarde, en 1763, Guillermo Watson, médico del Colegio Real de Médicos inglés y de la Royal Society, publicó "Effects of electricity applied to a tetanus", mostrando el rápido uso médico del invento. ${ }^{85}$ Los experimentos de Galvani mostraron que los músculos de las ranas se contraían con la chispa eléctrica, lo que llevó a que el citado científico dedicara uno de sus tratados al movimiento de contracción provocado por la electricidad. El error de Galvani fue pensar que la electricidad residía en los animales y no que se generaba fuera. Pero hasta aquí resulta interesante relacionar esta idea de la electricidad, entendida como una fuerza que subyace en el interior del ser humano y que ayuda a la contracción de los músculos y órganos, entre ellos el útero. Si seguimos con la lógica del baño, cuyo objetivo

82 Unanue, José Hipólito: Obras científicas..., T.I, págs. 122-123, 156-158.

83 Crespo, Pedro Nolasco: "Carta del Doctor don Pedro Nolasco Crespo sobre la senectud de los mortales y los medios de rejuvenecerlos", en Mercurio Peruano, XI, 378, Lima, 1794, Edición Facsimilar Biblioteca Nacional del Perú, 1966, págs. 140-147. Anotemos que el autor era oficial de contadores de La Paz, no era médico pero opina en temas médicos, lo que ratifica la difusión del tema en otros ambientes no clínicos.

84 Asimov considera que B. Franklin tomó la idea general de sus experimentos a partir de las observaciones hechas en relación al artefacto de Leiden. Asimov, Isaac: Enciclopedia biográfica de ciencia y tecnología, Madrid, Alianza Editorial, 1982, pág. 143.

85 La presencia de botellas de Leiden era muy común en los laboratorios de la época. Incluso A. Volta creó en 1774 un "electróforo", artefacto que reemplazó a la botella y que se hizo muy popular (Ibídem, pág. 187). 
revitalizador está bastante claro, entenderíamos por qué es posible aplicar choques eléctricos a las personas, en especial durante los baños. Si el baño lo que hace es tratar de revitalizar una fuerza interna, a partir del movimiento del agua que se interna en el cuerpo, con mayor razón la electricidad será usada para "llamar" o revitalizar esa fuerza vital del ser humano. Cullen, el afamado médico, también se interesó en la energía que se trasmitía al interior del ser humano. Lo importante es que él pensaba que la melancolía tenía que ver con las descargas de energía, asociando agotamiento con la conducta energética de los individuos. ${ }^{86}$

En Lima se conocía el uso de la electricidad por lo menos desde $1793 .{ }^{87}$ Esta es la fecha del artículo del director del Tribunal de Minería, Joseph Coquette, francés de nacimiento, quien anunciaba que la electricidad era el "principal agente que emplea la naturaleza para producir todos los fenómenos que nos presenta", afirmando que aún se estaban estudiando sus efectos. ${ }^{88}$ Por otro lado, un artículo anónimo exponía la nueva técnica del magnetismo animal, que consistía en fricciones suaves que se comunicaban a los fluidos internos y lo redistribuían por el interior del cuerpo. Esta técnica se aplicó en la ciudad de Manila a dos enfermas de amenorrea.$^{89} \mathrm{El}$ principio es el mismo del uso de la electricidad: comunicar un movimiento que a su vez convulsione el interior del cuerpo humano y lo haga reaccionar.

A través de esta terapia se trataba de devolver al cuerpo su elasticidad y resistencia. Para tratar los casos de mujeres parecía ser bastante útil, dado que por medio de un elemento mecánico se podía llegar a activar y dar calor al interior del cuerpo femenino. Ese cuerpo frío, húmedo, con tendencia a la melancolía, débil por causa del útero, podía ser "revivido" mediante esta terapia. No tenemos testimonios de cómo se sintieron las mujeres luego de ser sometidas a estas prácticas; de hecho, no tenemos prueba concreta de

86 Unanue considera que la medicina trata de recuperar la energía interna del ser humano. (Obras científicas..., T.I, pág. 127). Cullen, el afamado médico, también se interesó en la energía que se trasmitía al interior del ser humano. Lo importante es que pensaba que el estado melancólico tenía que ver con las descargas de energía, asoció agotamiento con melancolía. Jackson, Stanley: Historia de la melancolía..., pág. 125

87 Lanning indica que desde finales del XVIII se conocía su uso en América. Lanning, John Tate: El Real Protomedicato. La reglamentación de la profesión médica en el Imperio Español, México, Universidad Autónoma Metropolitana, 1997, pág. 515.

88 Coquette, Joseph: "Electricidad astronómica", en Mercurio Peruano, IX, 292, Lima, 1793, Edición Facsimilar Biblioteca Nacional del Perú, 1966. Además, se indica cómo fabricar los instrumentos para los experimentos eléctricos y que el físico puede modificar la intensidad de las "chispas", tal como indica Bonpland.

89 "Memoria histórica y crítica sobre la introducción del magnetismo en Manila", en Mercurio Peruano, XII, 389, Lima, 1794, Edición Facsimilar Biblioteca Nacional del Perú, 1966, págs. 66-108. 
que se hayan ejecutado en Lima. Sin embargo, nos parece interesante mostrar cómo esta terapia - y otras - ejemplifican la nueva concepción del cuerpo que se construyó a partir del siglo XVIII.

\section{Reflexiones finales}

El discurso médico a principios del siglo XIX ofreció una nueva justificación a la exclusión de la mujer de los espacios públicos. En base a la fisiología distinta de las mujeres, definida por la anatomía y la medicina, se estableció un comportamiento diferenciado para cada uno de los sexos. Mientras que en Europa ha sido bastante estudiado, no había que sepamos referencias de su existencia para el espacio colonial peruano. El trabajo que presentamos abre la posibilidad de buscar mayores evidencias en ese sentido; no podemos de ninguna manera pensar en un tema acabado - que por lo demás nunca existe en historia - con el análisis sólo de algunos elementos.

Los documentos que hemos analizado muestran que sí aparece una nueva imagen del cuerpo de la mujer hacia inicios del siglo XIX. Si la tendencia general es definirla como húmeda y fría, los trabajos de Unanue y los informes médicos que mostramos enfatizan una inclinación hacia la melancolía, que sería propia del espacio peruano. Se explica esta diferencia por la situación geográfica del Perú y por el paradigma médico hipocrático, que resaltaba ese factor. En el siglo XIX se desarrollarán más estos planteamientos, hasta llegar a la definición de la histeria como la enfermedad de la mujer.

En el caso peruano sólo contamos, hasta donde yo sé, con un estudio dedicado al tema del cuerpo femenino y el discurso médico; ${ }^{90}$ en él se analizan los primeros años del siglo XX, mostrando los estudios de los médicos de la época acerca de la maternidad y la identidad femenina. Existe un vacío entre este período, del que ya sabemos algo, y el período colonial, del cual en este aspecto estamos desinformados. Este estudio intenta tender puentes que acaben con esta dificultad. Si en el siglo XX está bastante claro que la mujer está relegada al hogar, especialmente en el caso de embarazo por razones de salubridad y del discurso médico, ${ }^{91}$ debemos agregar

90 Mannarelli, María Emma: "Cuerpo femenino...".

91 Se temía que por "las múltiples puertas de entrada" los organismos patógenos afecten especialmente a la mujer. Mannarelli, María Emma: "Cuerpo femenino...", pág. 91. 
por nuestra parte que este conocimiento comenzó a generarse desde finales del siglo XVIII. Comenzó por diferenciar fisiológicamente a hombre y mujer, para en razón de esa divergencia establecer los roles de cada uno. A la mujer, marcada por la debilidad de su cuerpo proveniente de su útero y de la menstruación, se le debe dar calor, pues es de naturaleza fría. Sería interesante relacionar este discurso con el patriarcado de la época, pues si la mujer necesita calor es posible que necesite ser acogida y protegida en razón de su debilitado organismo.

Por último, la imagen del cuerpo como máquina regida por las leyes de la mecánica también está presente en el Perú. La teoría de la aplicación de la electricidad muestra que se pensaba en la existencia de energía que circulaba al interior del ser humano. Ignoramos cuál fue el resultado del tratamiento de María Cabrera, ni sabemos cuánto sufrió con las disposiciones de los médicos; pero sí es posible que los médicos que la atendieron fueran parte importante de su vida, al punto de recurrir a ellos en un juicio de divorcio. La medicina y la iglesia se encuentran en el cuerpo y la enfermedad de una mujer. 



\section{$\operatorname{Anexos}^{92}$}

\section{Respuesta a la consulta hecha por la Sra. Doña María Cabrera}

Uno de los motivos que ha causado grandes desórdenes en la economía animal ha cido siempre la imaginación vehemente. Sus progresos se han extendido hasta el punto de creer por verdaderas unas enfermedades simuladas. El sexo femenino, digo el bello sexo, es mucho más susceptible de estos padecimientos, pues las mas pequeñas dolencias las preocupan y les hace caer en un entuciasmo. Esto lo motiva ya su poco padecimiento, ya el creerse ineptas para los quehaceres domésticos, ya que se concideran desgraciadas por considerar se descompaginará su hermosura y que no hallarán remedio para restaurarse. Estas y otras meditaciones fúnebres las ponen a las infelices en un estado de desesperación y abandono, que aquello que se podía remediar por un leve socorro del arte, se hace una enfermedad crónica difícil de extirparla. El encojimiento de ánimo en este sexo, su pudor, señoría, que tienen para manifestarse a un profesor luego que se ven acometidas de alguna enfermedad en las partes pudendas, hace nada menos que el incremento de sus males: el caso presente me lo caracteriza.

Es constante, que hay jóvenes que antes del estado de la pubertad se hallaban sujetas a una leucorrea, que es el asunto a que me contrahigo, y del que se me pide mi parecer.

Definimos a la leucorrea en todo fluxo blanco seroso o puriforme de la vagina. Yo me limito unicamente a tratar del que se puede presumir venir de los mismos vasos que en su estado natural subministran la sangre menstrual. El fluxo de la vagina es de este género, quando acomete a las mujeres sugetas al fluxo inmoderado del menstruo, y en las que este se origina de las causas que debilitan los vasos del útero. Quando el fluxo menstrual disminuye, es a proporción de lo que aumenta el fluxo blanco, en cuyo caso se disminuye la disposición a los [incompleto] activa. Acostumbrada la naturaleza a estas evaquaciones por instantes se aumenta la menorragia. El útero pierde su elasticidad, en defecto de la menstruación se aumenta la leucorrea, se padece una afección local, y lo que era únicamente emanso mensium [sic], viene a tener unos resultados funestos. La misma debilidad del útero no le permite reaserce [sic] en quanto a los estragos que hacen los placeres de venus. La sífilis se propaga facilmente. Aunque asentimos que en el princi-

92 Archivo Arzobispal de Lima, Divorcios, Legajo. 83, 1803-1808, 167ff. 
pio de la vida se padesca leucorrea, esto es únicamente de las glándulas mucosas, pues algunos autores le dan el nombre de corisa del útero, los gallicanos le llaman chaude-pisse si adquiere otra calidad en sentir de Heyster de fluxo maligno o venereo quando a proporción que ya se abanza al estado de la adolescencia se une a contraer matrimonio con algún galicado. En este caso esta materia benigna se buelve maligna y poniéndose acre con facilidad corroe las partes internas y externas del útero. Ya aqui tenemos un estado complicado y que pide (como se me anuncia) socorros diversos mas activos propios para destruir el morbo.

A saver

$1 .^{\circ}$ Evitar todo lo que sea capaz de iracundez, que se altere la bilis y que se vensan las pasiones del ánimo, apartándose de los objetos que le puedan causar tedio.

2. ${ }^{\circ}$ Mudar de cituasión, esto es, a un temperamento suave y lexos de emanaciones y de una atmosfera limpia.

3. ${ }^{\circ}$ Abstenerse de los deleytes de venus aunque creo no tendría [apetito?] al coito $^{93}$ pues en esta enfermedad la anafrodicia es un syntoma característico, resultado del infarto que padecen los ovarios, tubos falopianos y la arteria del útero, de donde se deduce la esterilidad que es anexa a toda muger y que también [la?] sífilis tiene conexión con los exantemas, caída de cejas, [incompleto] polaca, etc.

4. ${ }^{\circ}$ El paseo al campo y movimiento de la gestación y procurar ver todos aquellos objetos que embíen al alma unas ideas agradables, pues en sentir de Hunter, hay mugeres que padecen este mal y luego que salen al campo les sesa y retorna quando regresan. La vida sedentaria disminuye la actividad de la circulación y la tristeza las aumenta. Los italianos admienten que estos fluxos proceden de cacoquimia o del estado del hígado y caveza, pero es absurdo detestable de la sana práctica pues estos son unos sectarios llenos de preocupaciones en contra de nuestros dogmas católicos.

5. ${ }^{\circ}$ La unturas [?] mercuriales me parecen convenientes, pero antes es nececario dar un baño de agua fría, para dar tono o reanimar a las partes que han caido en un estado de inerción [sic]. Quando se hallan de dar las unturas [?] y se aproxime el [dialismo?] se purgará. Con ellas puede lograrse oponerse a la calentura lenta nerviosa, y que buelva el menstruo periódico y aunque estando en las unturas [?] viniese el fluxo mentrual no se abstendrán de ellas.

6. ${ }^{\circ}$ Que siendo anexo a este fluxo la esterilidad, como dicho es, por debilitar el systema de la generación, combiene dar sus saumerios de incienso ámbar y bermellón. Las purgas serán de ruibarbo con el bálzamo del Perú, el mercurio y la escamonea. Después conviene los adstringentes: también los marciales como el tártaro calibeado, el vitriolo marcial, y las aguas herrumbrosas, como asi mismo los ligeros diaforéticos, como la bardana y la quina, el ether vitriólico lo puede tomar en un poco de azúcar.

93 Subrayado original. 
7. ${ }^{\circ}$ La vagina se dará unas inyecciones del cosimiento de romero hormino matricaria, yerba buena, salvia, milefolio, tormentila y un poco de piedra de alumbre.

8. ${ }^{\circ}$ Se concluirá la curación por los poderosos fortificantes como son la tintura de marte de Zuvelfero, la aperitiva de marte de Ludovico, en un cosimiento de torongil o flor de naranja o sus ojas.

9. ${ }^{\circ}$ La electrisidad es muy oportuna respecto que da tono a las perdidas con la comoción [sic] que causa en el systema. No me detengo en sus prerrogativas por ser muy difusa esta materia y por que mi talento y conocimiento son muy escasos y por que la mayor parte de los médicos de este nuevo mundo no adoptan sus admirables virtudes por hallarse distantes de la verdad, aunque a pesar de las críticas y emulaciones vulgares sin razón ella prevalescerá pues sin embargo de su crítica ningún descubrimiento han hecho ha veneficio de la humanidad.

Nota: En el tiempo de las unturas los baños serán templados y lo más acertado es ponerse en las manos de un profesor experto y cristiano.

Este es mi parescer, salvo el mejor que prestaren los grandes corifeos del arte.

San Jasto y setiembre 11 de 1803.

José de Figueroa.

\section{Copia de la respuesta de la consulta de Da. María Cabrera que le hiso al físico Mr. Bomplán, médico del Barón de Hombolt [sic]}

Las enfermedades que acontecen a las partes de la generación son las que más afectan a la imaginación y debilitan con lentitud pero con más tenacidad al sistema general que necesita organisación.

La leucorrhea que adolesce la enferma se halla descrita por el quadro nosológico de Srediaur [sic] al artículo Blenorrhea. Esta enfermedad que ha precedido en esta joven el flujo menstrual de algunos años, ha debilitado extraordinariamente los vasos del útero y el sistema de fibras o nerbios de la matrice, ha ocasionado una amenorrhea, que después complicada con el ácido sifilítico o mal venéreo hace producido todos los grandes desórdenes que acarrean estas enfermedades terribles y amortiguadoras.

En efecto el estado actual de la enferma es deplorable, la palidez de su rostro y de toda la habitud [sic] de su cuerpo, los dolores continuos de cabeza, espaldas, caderas, etc. La caída de su pelo y cejas y la exfoliación de su dentadura, la obstrucción dolorosa de sus ingles, anuncian lo abansado que esta la enfermedad, por otro lado la dispepsia, su respiración precipitada y sobretodo la debilidad de ánimo y anafrodicia total que padece la hacen digna de compasión y piden los más 
poderosos y prontos auxilios. Mi próxima partida no me da lugar a estenderme mas y así paso al régimen que debe seguir la enferma para salir del infeliz estado en que se halla.

1. ${ }^{\circ}$ Mudará de temperamento y ebitará todo que puede evitar en ella el movimiento de cólera.

2. ${ }^{\circ}$ Hará diariamente, esto es por la mañana y por la tarde exercicios moderados a pie y a caballo o en carruage y procurará por todos los medios posibles amenisar sus ideas dibirtiéndose para distraerse y olbidar si fuese posible su enfermedad.

3. ${ }^{\circ}$ Seguir el régimen antiflogístico y tomará tres veces al día alimentos de fácil digestión en moderada cantidad para de este modo restablecer las funciones del estómago debilitado.

4. ${ }^{\text {o }}$ Tendrá cuidado de mantener su vientre libre por medio de las sales neutras, etc.

5. Hará uso durante quatro meses consecutivos del unguento antisifilítico y tónico de Mr. Gerbier. Este ungüento se compone de mercurio apagado en la goma arábiga según el método de Mr. Plenari y se triturarán después con manteca de baca, opio y alcanfor. Los baños fríos, la leche, las emulciones se usarán todo el tiempo de la curación.

6. ${ }^{\circ}$ La enferma llebará siempre un frasco de ether vitriólico y tomará de 50 a 60 gotas de este remedio sobre un pedazo de azúcar, quando esté acometida de movimientos espasmódicos en la matriz o en cualquier otra parte del cuerpo.

$7^{\circ}$ En el período abansado de esta enfermedad, todos estos remedios serían ineficaces sino hiban de par con la electrisidad, con este agente tan poderoso y que no conosieron nuestros padres, con este fluido admirable, único estimulante conocido en la medicina capas de restablecer el mobimiento y reanimar las partes inertes o muertas del cuerpo humano, Rovilley, Adams, [ilegible],Cavallo, Bertholon, Cullen y todos los médicos modernos recomiendan este imponderable remedio en la leucorrhea, particularmente cuando hay una anafrodicia es el único específico que pueda mirarse como seguro.

La enferma se hará electrisar por un físico experto del modo siguiente. 1. ${ }^{\circ}$ tomará por la mañana sobre el ayslador un baño eléctrico de una hora y en este espacio de tiempo se le sacarán doscientas chispas.

2. ${ }^{\circ}$ Por la tarde resibirá treinta commociones y se la sacará igualmente doscientas chispas fuertes.

Las commociones serán al principio fuertes, mas como las fricciones mercuriales las hacen mui sensibles se arreglará la intencidad sobre las fuerzas de la enferma.

Santa y setiembre 6 de $1802 .^{94}$

94 Véase Cullen, Tomo 2. ${ }^{\circ}$ pag. 357 , Tomo $4 .^{\circ}$ pag. 210 y 211 . Bertholon, Tratado de le electrisidad del cuerpo humano en su estado de salud y enfermedad, Artículo anafrodicia y leucorrea. 